\title{
Conceito de velocidade efetiva social como argumento de reforço à implantação de políticas de mobilidade urbana sustentável no Brasil
}

\author{
Leonardo Herszon Meira ${ }^{1}$, Mauricio Oliveira de Andrade ${ }^{2}$, Jessica Helena de Lima ${ }^{3}$ \\ ${ }^{1}$ Universidade Federal de Pernambuco, Recife, PE, Brasil, leonardohmeira@gmail.com \\ 2Universidade Federal de Pernambuco, Recife, PE, Brasil, mauandrade@gmail.com \\ 3Universidade Federal de Pernambuco, Recife, PE, Brasil, delima.jh@gmail.com
}

\section{Recebido:}

02 de junho de 2016

Aceito para publicação:

03 de julho de 2017

Publicado:

31 de agosto de 2017

Editor de área:

Helena Beatriz Cybis, UFRGS

\section{Palavras-chaves:}

Velocidade Efetiva.

Custos dos Transportes.

Políticas Públicas.

\section{Keywords:}

Effective Speed.

Transport Costs.

Public policy.

DOI:10.14295/transportes.v25i2.1164

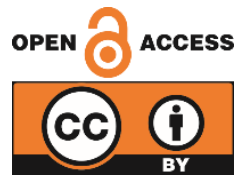

\begin{abstract}
RESUMO
A qualidade dos deslocamentos de várias cidades brasileiras vem diminuindo nos últimos anos e levando a um ambiente cada vez mais insustentável. Uma forma de combater esse cenário é adotar soluções inovadoras de políticas públicas de mobilidade. Este trabalho se dedica a estudar a possibilidade de mudança de comportamento das pessoas com a inclusão da velocidade efetiva social nas políticas públicas de mobilidade. A Lei 12.587/2012 prevê a internalização dos custos externos causados pelos usuários. Nesse contexto, a velocidade efetiva social surge como uma medida inovadora. Velocidade efetiva social é um conceito que soma ao tempo de viagem de um modo de transporte o tempo de trabalho gasto para pagar o custo privado e social da viagem. Usou-se como estudo de caso para os dados demográficos uma pesquisa realizada com frequentadores da UFPE. Resultados sugerem ter a velocidade efetiva social capacidade para ser integrada nas políticas públicas de mobilidade brasileiras.
\end{abstract}

\section{ABSTRACT}

Commuting quality in several Brazilian cities has been decreasing in recent years, leading to an increasingly unsustainable environment. One way to contest this scenario is to adopt innovative solutions in public mobility policies. This work is dedicated to study the possibility of changing the people's behavior by including social effective speed in mobility public policies. Law $12.587 / 2012$ provides for the internalization of external costs caused by the users. In this context, social effective speed appears as an innovative measure. Social effective speed is a concept that adds to a certain mode of transport travel time the working time spent to pay the trip's private and social costs. A survey conducted with UFPE's attendees was used as a case study for demographic data. Results suggest that social effective speed is suitable to be integrated in Brazilian mobility public policies.

\section{INTRODUÇÃO}

O crescimento da taxa de motorização da população decorrente do aumento de renda, da redução de impostos e da facilidade de crédito nos anos recentes tem ajudado a produzir graves externalidades negativas na mobilidade urbana das cidades brasileiras. A literatura destaca como relevantes nestes casos o aumento dos congestionamentos (Euroforum, 2007), acréscimo do consumo de combustíveis (Hao et al., 2011), tempos crescentes de viagem (Castro, 2007), elevação do número de acidentes (Marín e Queiroz, 2000), crescimento da emissão de poluentes com reflexos negativos na saúde das pessoas (GrahamRowe et al., 2012), falta de confiabilidade e pontualidade do transporte público (Meira et al., 2014), maior custo operacional e aumento das tarifas do transporte público (Ragazzo e Lima, 2013).

Sobre isso, Lima Neto et al. (2014) afirmam que as políticas públicas adotadas nos últimos anos estão reforçando as vantagens do uso do transporte individual em relação ao transporte público. Desde 2002, 
as tarifas de transporte público cresceram aproximadamente $26 \%$ acima da inflação. Somente a partir de 2013, com a intensificação das manifestações populares contra os aumentos de tarifas, houve redução real dos preços das passagens, apesar dos custos continuarem crescentes. Por sua vez, o preço dos veículos privados e da gasolina, principais insumos para uso dessa modalidade, subiram menos que a inflação. Políticas públicas focadas nessa problemática podem mitigar parte das externalidades produzidas.

Por outro lado, o Ministério dos Transportes (Brasil, 2007) salienta ainda que o elemento crucial no planejamento de políticas públicas é a identificação de problemas que afetam um determinado público e que quando reconhecidos e declarados pelo governo passam a fazer parte de sua agenda de compromissos. Uma vez que os problemas são identificados, as causas devem ser buscadas para posteriormente serem propostos os objetivos e as ações.

Takahashi (2004) coloca que a formulação de políticas públicas trata do resultado do embate das diferentes versões de projeto de sociedade imaginadas pelos diferentes atores que contracenam num cenário político concreto, traduzido num conceito que se materializa. Assim, seus objetivos encontram limites de duas naturezas: por um lado, a estrutura do mundo, com suas leis naturais de conservação e de mudança impõe restrições ao "possível" perante o "imaginado". Por outro, a multiplicidade de atores impõe a formação de "soluções de compromisso", impossibilitando o "pleno atendimento" para qualquer dos atores.

A partir da promulgação da Constituição Federal de 1988, algumas políticas públicas vêm sendo institucionalizadas através de legislação federal com o objetivo de melhorar a qualidade de vida da população urbana brasileira, dentre elas: Estatuto da Cidade (Lei no. 10.257/2001), Política Nacional de Mobilidade Urbana (Lei no. 12.587/2012) e Estatuto da Metrópole (Lei no. 13.089/2015). Outro marco importante foi a criação do Ministério das Cidades, reconhecendo que os desafios urbanos precisam ser encarados como política de Estado.

Mesmo contando com os instrumentos de planejamento impostos pelo Estatuto das Cidades -planos diretores para cidades acima de 20.000 habitantes e planos de transportes integrados para cidades acima de 500.000 habitantes - e com a atuação do Ministério das Cidades, no arcabouço jurídico brasileiro ainda faltava um instrumento específico que tratasse dos princípios, diretrizes e instrumentos de uma política de mobilidade urbana em nível nacional. Configuravam-se, desta forma, as condições necessárias e suficientes para justificar uma legislação exclusiva sobre o tema (IPEA, 2012). Então, foi sancionada a Lei Federal no. 12.587/2012 (Brasil, 2012), com princípios de que as externalidades geradas pelo trânsito precisam ser custeadas por quem as produz.

Diante do exposto, no escopo de medidas que podem melhorar as políticas públicas de mobilidade e dar um argumento prático aos princípios da legislação vigente estão os conceitos de velocidade efetiva e de velocidade efetiva social. Sobre velocidade efetiva, Lima et al. (2015) colocam que desempenho real do automóvel é muito inferior à sua velocidade percebida. Além disso, os indivíduos tendem a superestimar os custos e o tempo gasto no transporte público e subestimar os custos do automóvel. Nesse contexto, Tranter (2010) define velocidade efetiva como um conceito holístico que leva em conta todos os custos associados a cada modo de transporte. Em vez de concentrar unicamente no tempo gasto na viagem, a velocidade efetiva considera todo o tempo necessário para fazer uma viagem usando um modo de transporte. Assim, o conceito considera não só o tempo gasto durante cada viagem, mas também o tempo necessário para pagar pela viagem, incluindo depreciação, combustível, seguro, impostos, estacionamento, pedágios etc. Enfatiza também que além desses custos diretos há ainda os custos indiretos (ou externalidades) que são compartilhados entre toda a sociedade (agora e no futuro). Esses incluem, por exemplo, os custos de saúde associados ao uso do veículo. Quando essas externalidades são consideradas, o conceito de velocidade efetiva evolui para velocidade efetiva social.

Assim, este artigo tem como objetivo principa analisar a eficácia do coneito de velocidade efetiva social enquanto argumento de reforço à Política Nacial de Mobilidade Urbana. Como objetivos específicos propõrm-se: (1) fazer uma revisão de literatura, com foco nos conceitos de custos de tempo de viagem, custos generalizados de transportes, velocidade efetiva, velocidade efetiva social e gestão da mobilidade 
urbana; (2) quantificar os custos das externalidades; e (3) somar, aos argumentos da Política Nacional de Mobilidade Urbana, os preceitos econômicos de externalidades.

Este artigo está estruturado em cinco seções incluindo esta introdução. Na seção 2 são abordadas externalidades, custos de transportes, velocidade efetiva e velocidade efetiva social. Em seguida, a seção 3 traz a metodologia do estudo realizado, com o cálculo da velocidade efetiva e da velocidade efetiva social, aplicado a uma amostra pesquisada na Universidade Federal de Pernambuco (UFPE). A seção 4 analisa os resultados do trabalho. Por fim, a seção 5 tece as considerações finais e traz recomendações para trabalhos futuros.

\section{CUSTOS DE TRANSPORTES, VELOCIDADE EFETIVA E VELOCIDADE EFETIVA SOCIAL}

Uma decisão individual de realizar uma viagem não depende apenas dos custos de transação envolvidos, mas também de outros custos e fatores valorizados, como o tempo que será despendido, o nível de conforto e a confiabilidade proporcionada pelo transporte. 0 desenvolvimento de estudos de demanda de transporte baseados no comportamento dos indivíduos em relação ao conjunto de diferentes opções modais conduz à necessidade de valorar, numa base comum, os custos monetários, os custos associados ao tempo e o próprio conforto, levando ao desenvolvimento do conceito de custo generalizado de transporte (Merlin, 1985). Este custo expressa o valor resultante da combinação dos diferentes custos monetários de tempo, psicológicos, ou outros, que contribuem para a valoração individual de cada decisão de viagem. Desta forma, torna-se necessário atribuir um valor monetário às diferentes parcelas do custo do deslocamento, que será formado pelo valor da tarifa paga no caso do transporte público ou pelas despesas diretas da utilização do transporte individual, acrescido do custo do tempo gasto na viagem (Marques da Costa, 2007).

Para o Victoria Transport Policy Institute (VTPI, 2013) os custos de tempos de viagem, configurados como valores do tempo gasto no transporte, incluindo os tempos de espera e de deslocamento despendidos por usuários ou pelas empresas e seus trabalhadores representam um dos maiores custos de transportes. São, por essa razão, considerados como justificativa principal de investimentos em transportes, já que os benefícios se referem ao valor da economia pela redução dos custos de tempo de viagem. Destaca também que a valoração do tempo sob o aspecto econômico considera normalmente fatores relacionados aos interesses e perfis dos indivíduos, como renda, condições ofertadas, finalidade, incertezas e desconfortos associados às viagens.

Ocorre que essa abordagem apresentada sobre custos generalizados de transporte e custo do tempo de viagem foca apenas nas decisões individuais baseadas na utilidade extraída de cada decisão de viagem, não levando em consideração as necessidades de equidade e eficiência das escolhas modais do ponto de vista social. Alguns custos de viagem podem ser considerados ineficientes se impõem constrangimentos a outros usuários. É necessário, portanto, ir além e discutir indicadores que incorporem as externalidades produzidas por algumas escolhas modais na busca de demonstrar a ineficiência sistêmica de tais opções, superando a simples racionalidade do indivíduo. Para tal fim, este artigo parte do conceito da velocidade efetiva de Tranter (2004) incorporando os custos das externalidades relativas à utilização de vários modos de deslocamento no meio urbano, com o objetivo de atingir a todos os custos que incidem sobre os transportes.

Segundo Leite e Ferreira (2014), as primeiras ideias compatíveis com velocidade efetiva datam de 1854, ano em que Henry Thoreau publicou o livro Walden. Nele, o autor discute que caso saísse pela manhã caminhando rumo à cidade chegaria mais rápido que alguém que fosse de trem, pois essa pessoa precisaria trabalhar uma jornada inteira para poder pagar a passagem e ainda correria o risco de, ao chegar à estação, não existirem mais vagas ou serviços na jornada. Illich (1974) também colabora com o conceito ao mostrar que o americano despende $25 \%$ do seu tempo social com o transporte e sua manutenção, enquanto sociedades não motorizadas gastam entre 3\% e 8\%.

Para explicar essa distorção, Tranter (2004) propôs o conceito de velocidade efetiva, superando o conceito de velocidade média, representado pela relação entre distância percorrida e tempo de viagem. 
Nesse novo conceito, simplificado na Equação 1, inclui-se além do tempo de viagem, o tempo de trabalho necessário para pagar os custos da viagem.

$$
V_{e f}=\frac{D_{i, j}}{T_{t}+T_{i, j}}
$$

Onde:

$D_{i, j}($ distância entre casa e trabalho): total de quilômetros percorridos por dia (ida e volta);

$T_{t}$ (tempo de trabalho): tempo total de trabalho dedicado a pagar os custos do transporte; e

$T_{i, j}$ (tempo de deslocamento): tempo gasto entre a origem e o destino (ida e volta).

A argumentação é que através do conceito de velocidade efetiva as pessoas possam ser alertadas sobre os verdadeiros custos despendidos no deslocamento. Assim, alguns podem repensar seu comportamento e adotar formas mais sustentáveis de mobilidade, sintonizadas com a Política Nacional de Mobilidade Urbana (Brasil, 2004). Como consequência, espera-se o aumento no uso dos meios de transportes públicos e não motorizados.

Apesar de demonstrar a ineficiência econômica em nível individual, o conceito de velocidade efetiva apresentado não contabiliza os custos ou externalidades que os usuários dos transportes impõem aos demais. Como os custos externos não são considerados na estrutura de custos de produção, eles não afetam os preços de mercado. Portanto, não são pagos pelo produtor ou pelo consumidor, recaindo a terceiros. Esta consequência distorce as decisões do mercado e, portanto, impede o alcance do ponto ótimo social (Petrucelli, 2015).

No tocante à velocidade efetiva social, Ker e James (2000) afirmam que as externalidades produzidas por um veículo motorizado privado nas cidades têm um custo pelo menos tão elevado quanto seus custos operacionais variáveis. Litman (2006) ainda sugere que os custos externos são $50 \%$ maiores que os custos variáveis financeiros diretos e são equivalentes a 70\% dos custos totais diretos.

Do ponto de vista dos transportes, essas externalidades incluem impactos econômicos (congestionamento e danos à infraestrutura viária) e sociais (gastos com mortes e internações, problemas de saúde devido à poluição, ao ruído) do transporte motorizado. No caso do transporte público os subsídios também são incluídos (Tranter e Ker, 2007). Assim, surge o conceito de velocidade efetiva social.

\section{CÁLCULO DA VELOCIDADE EFETIVA E DA VELOCIDADE EFETIVA SOCIAL}

Para analisar um exemplo prático de cálculo da velocidade efetiva foi utilizada uma pesquisa realizada por Meira et al. (2014) no Campus Joaquim Amazonas da UFPE, em Recife. 0 campus possuía na época 21.039 alunos de graduação e 6.646 de pós-graduação, os docentes eram 2.191 e os servidores técnicoadministrativos 3.892. Os dados da UFPE ainda informavam 1.154 trabalhadores terceirizados e prestadores de serviço. Ao considerar o comércio e outras atividades informais na Universidade, esse número torna-se ainda maior. Esse grande contingente de pessoas faz da UFPE, possivelmente, o maior Polo Gerador de Viagens da Região Metropolitana do Recife (RMR).

Na amostra com 1.000 frequentadores da UFPE foram coletados dados de 792 discentes, 60 docentes, 107 servidores e 41 prestadores de serviço. Além do tipo de usuário foram coletados perfis de renda, tempos de viagem, locais de origem e modos de transporte utilizados. A UFPE foi escolhida por atrair pessoas de toda RMR e por sua comunidade acadêmica contar majoritariamente com pessoas jovens que, portanto, tendem a buscarem novas experiências em termos de escolhas modais. 


\subsection{Cálculo da velocidade efetiva}

Com os dados da pesquisa pôde-se calcular a velocidade efetiva de cada modo de transporte citado. Desses, o que tem a composição mais complexa é o automóvel particular. Para estimá-lo, usou-se o custo do GM Onix, veículo mais vendido no Brasil em 2015, com preço-base de R \$38.999,00 (GM, 2016). Dele, calcularam-se os custos fixos anuais, que são (Leite e Ferreira, 2014): custo de oportunidade de capital de 11\%, IPVA de 2,5\%, taxa de seguro de 4\% e depreciação anual de 16,7\% para uma vida útil de 10 anos. Os custos variáveis por quilômetro foram calculados considerando os itens propostos por Ávila (2016) e que englobam: lubrificantes, combustível, manutenção etc. No caso do automóvel, chegou-se a um valor de $\mathrm{R} \$ 0,45 / \mathrm{km}$. Também se assumiu que cada usuário faz duas viagens diárias (ida e volta), em 22 dias úteis mensais e nos 12 meses do ano. Para o cálculo dos custos variáveis foi utilizada a distância média informada na pesquisa pelos usuários. Então, pôde-se calcular o total de quilômetros percorridos por ano em média para cada tipo de usuário. 0 custo total é composto pelo custo fixo anual somado ao custo variável por quilômetro multiplicado pela quantidade de quilômetros percorrida por ano.

Os custos da motocicleta possuem os mesmos componentes do automóvel (usou-se como veículopadrão a Honda CG 150 , preço-base de $R \$ 6.852,00$ ) e chegou-se a um valor de custo variável de $R \$$ $0,15 / \mathrm{km}$. Considerou-se ainda que uma bicicleta-padrão custa $\mathrm{R} \$ 500,00$, possui custos variáveis irrisórios e estimaram-se seus custos fixos anuais de depreciação e manutenção como sendo $\mathrm{R} \$ 150,00$ (30\%). Por outro lado, os custos de deslocamento a pé foram considerados irrelevantes.

Sobre o transporte público, o Sistema Estrutural Integrado permite que as pessoas se desloquem por toda RMR pagando apenas uma passagem. Isso quer dizer que seu custo não varia com a distância percorrida. Assim, foi considerado para as viagens de transporte público o valor da tarifa da RMR em 2016 de $\mathrm{R} \$ 2,80$ ( $\mathrm{R}$ \$ 5,60 na ida e volta). Já o custo do táxi veio da distância média da amostra pesquisada vezes a tarifa no Recife em 2016 ( $\mathrm{R} \$ 4,75$ da bandeirada + $\mathrm{R} \$ 2,31$ por quilômetro rodado).

Ressalta-se que os resultados apresentados para viagens a pé e de bicicleta provêm dos valores indicados pelos participantes da pesquisa. Isso talvez explique a discrepância entre os tempos informados (percebidos) com os comumente adotados pela literatura, conforme revisão de Lima et al. (2015). Com essa ressalva, decidiu-se utilizar os tempos percebidos pelos entrevistados. Os custos calculados de cada modo estão na Tabela 1.

Tabela 1: Custos médios por quilômetro dos modos de transporte da amostra

\begin{tabular}{lrrrrrc}
\hline Modo & Custos Fixos & Custos Variáveis & $\begin{array}{c}\text { Custos Anuais } \\
\text { Totais }\end{array}$ & $\begin{array}{c}\text { Distância Média } \\
\text { Diária Pesquisada } \\
(\mathbf{K m})\end{array}$ & $\begin{array}{c}\text { Distância Média } \\
\text { Anual Pesquisada } \\
(\mathbf{K m})\end{array}$ & $\begin{array}{c}\text { Custo Médio } \\
\text { por Km } \\
(\mathbf{R} \$ \mathbf{k m})\end{array}$ \\
\hline Automóvel & $\mathrm{R} \$ 13.337,66$ & $\mathrm{R} \$ 2.722,90$ & $\mathrm{R} \$ 16.060,56$ & 22,92 & $6.050,88$ & 2,65 \\
Transp. Púb. & $\mathrm{R} \$ 0,00$ & $\mathrm{R} \$ 1.478,40$ & $\mathrm{R} \$ 1.478,40$ & 28,24 & $7.455,36$ & 0,20 \\
Motocicleta & $\mathrm{R} \$ 2.343,38$ & $\mathrm{R} \$ 854,57$ & $\mathrm{R} \$ 3.197,95$ & 21,58 & $5.697,12$ & 0,56 \\
Bicicleta & $\mathrm{R} \$ 150,00$ & $\mathrm{R} \$ 0,00$ & $\mathrm{R} \$ 150,00$ & 6,96 & $1.837,44$ & 0,08 \\
A pé & $\mathrm{R} \$ 0,00$ & $\mathrm{R} \$ 0,00$ & $\mathrm{R} \$ 0,00$ & 5,68 & $1.499,52$ & 0,00 \\
Táxi & $\mathrm{R} \$ 0,00$ & $\mathrm{R} \$ 11.448,25$ & $\mathrm{R} \$ 11.448,25$ & 14,66 & $3.870,24$ & 2,96 \\
\hline
\end{tabular}

Para calcular a velocidade efetiva considerou-se o valor do Salário Mínimo (SM) de 2016 a R\$ 880,00. Na pesquisa, 27,58\% das pessoas afirmaram ter renda familiar de até $\mathrm{R} \$ 2.640,00$ (3SM), 30,95\% entre 3 e 5 SM ( $R \$ 2.640,00$ a $R \$ 4.400,00), 22,17 \%$ entre 5 e 8 SM ( $\$$ \$ 4.400,00 a $\mathrm{R} \$ 7.040,00)$ e $19,31 \%$ acima de 8 SM (mais de R $\$ 7.040,00$ ).

Então, foi possível calcular a velocidade efetiva (Tabela 2), de acordo com a Equação 1. As colunas da Tabela 2 vêm do seu numerador e denominador. Sobre esse cálculo, salienta-se que a "Distância Média Diária" é o dobro da distância média da pesquisa para considerar o movimento pendular. Para o cálculo do "Tempo de Trabalho Diário" foi considerada a renda mensal média da amostra de R \$ 4.420,22 dividido por 220 horas, conforme prevê o Decreto-Lei no 5.452/1943 (CLT). Isso resulta na renda horária da amostra de $\mathrm{R} \$ 20,09$. Depois, dividiu-se o custo diário de cada modo de transporte pela renda horária. 
Obtém-se o custo diário de cada modo multiplicando-se os custos médios por quilômetro pela distância média diária pesquisada (Tabela 1). Com isso, calcula-se o número de horas que precisam ser trabalhadas para pagar o custo diário daquele modo de transporte. Já o "Tempo Médio de Deslocamento Diário" é o dobro do tempo médio pesquisado em minutos passando a unidade de tempo para hora.

Tabela 2: Cálculo da velocidade efetiva (universo da amostra)

\begin{tabular}{lccccc}
\hline Modo & $\begin{array}{c}\text { Distância Média Diária } \\
\text { Pesquisada (Km) }\end{array}$ & $\begin{array}{c}\text { Tempo de Trabalho } \\
\text { Diário (horas) }\end{array}$ & $\begin{array}{c}\text { Tempo Médio de } \\
\text { Deslocamento Diário (horas) }\end{array}$ & $\begin{array}{c}\text { Velocidade } \\
\text { Efetiva (Km/h) }\end{array}$ & Ranking \\
\hline Automóvel & 22,92 & 3,02 & 1,74 & 4,82 & 50 \\
Transp. Púb. & 28,24 & 0,28 & 2,63 & 9,70 & 20 \\
Motocicleta & 21,58 & 0,60 & 1,21 & 11,92 & 10 \\
Bicicleta & 6,96 & 0,03 & 0,75 & 8,92 & 30 \\
A pé & 5,68 & - & 0,68 & 8,35 & 40 \\
Táxi & 14,66 & 2,16 & 1,44 & 4,07 & 60 \\
\hline
\end{tabular}

\subsection{Cálculo da velocidade efetiva social}

Para o cálculo do custo das externalidades foram considerados os custos sociais relativos ao custo da poluição, ao custo dos acidentes e ao custo dos congestionamentos, considerados os mais relevantes na literatura. A maior parte dos cálculos dos custos sociais considerou apenas três modos: automóvel, motocicleta e ônibus. Os transportes não motorizados não causam poluição e os custos sociais de acidentes provocados por pedestres e bicicletas são irrisórios. No custo dos congestionamentos, bicicletas foram incluídas porque apesar de serem mais flexíveis pelo seu tamanho, o aumento da quantidade delas pode contribuir marginalmente para congestionamentos.

\subsubsection{Custos com poluição}

Segundo Knight e Young (2006), a perda de qualidade de vida representada pelo aumento da morbidade depende da concentração na atmosfera de $\mathrm{MP}_{10}$ (partículas em suspensão com diâmetro inferior a 10 $\mu / \mathrm{m}^{3}$ inaláveis pelo sistema respiratório). Essas partículas são provenientes do tráfego em estradas não pavimentadas, moagem e trituração de materiais e poeira transportada pelo vento (Morawska et al., 2001; Ostro; Chestnut, 1998). Quando concentradas estão associadas a problemas como asma (Halek et al., 2009) e rinite (Roseiro, 2003).

Na Região Metropolitana de São Paulo (RMSP), CETESB (2015) aponta que a concentração média anual de $\mathrm{MP}_{10}$ em 2014 foi de $36 \mu \mathrm{g} / \mathrm{m}^{3}$. Como não existem dados de poluição disponíveis para o Recife, nesse trabalho assumiu-se que a frota local tem uma divisão modal proporcional à de São Paulo. Segundo a mesma fonte, os automóveis foram responsáveis por 1,38\%, os ônibus por $11,15 \%$ e as motocicletas por $1,78 \%$ do total de $\mathrm{MP}_{10}$ emitido. Esses percentuais permitem inferir que $14,31 \%$ (ou 5,1516 $\mu \mathrm{g} / \mathrm{m}^{3}$ ) da concentração de $\mathrm{MP}_{10}$ foi emitida pela frota veicular. Ocorre que esses valores foram medidos para a frota da RMSP de 12.278.646 veículos (DENATRAN, 2016). Como a frota da RMR é de 1.263.105 veículos (ibid), fazendo-se uma proporção com o valor em São Paulo de $36 \mu \mathrm{g} / \mathrm{m}^{3}$, chega-se ao valor de 3,70 $\mu \mathrm{g} / \mathrm{m}^{3}$ para a concentração de $\mathrm{MP}_{10}$ na RMR.

Para calcular o custo social relacionado à poluição do ar pelo transporte, é preciso estimar qual seria o impacto na morbidade caso a poluição do ar por $\mathrm{MP}_{10}$ fosse reduzida. Lvovsky (2000) propõe que tal ganho poderia ser sintetizado pela Equação 2:

$$
\Delta \mathrm{S}=\mathrm{b}^{*} \Delta \mathrm{C} * \mathrm{P}
$$

Em que $\Delta$ S é o impacto na saúde, b é a função dose-resposta, $\Delta C$ é a variação na concentração do poluente $\mathrm{MP}_{10}$ e P é a população exposta a tal concentração. 
Lvovsky (2000) afirma ser o parâmetro b igual a 0,000012, que corresponde ao montante de internações hospitalares em razão da concentração de $\mathrm{MP}_{10}$. Essa relação indica que para cada $1 \mu \mathrm{g} / \mathrm{m}^{3}$ de concentração, ocorrem 0,000012 internações por problemas respiratórios. Sendo a concentração de partículas na RMR de $3,7 \mu \mathrm{g} / \mathrm{m}^{3}$, os automóveis respondem por $0,051 \mu \mathrm{g} / \mathrm{m}^{3}(1,38 \%)$, os ônibus por $0,413 \mu \mathrm{g} / \mathrm{m}^{3}(11,15 \%)$ e as motocicletas por $0,066 \mu \mathrm{g} / \mathrm{m}^{3}$ (1,78\%). Por fim, a população exposta é a da RMR, estimada em 3.914.317 pessoas (IBGE, 2015).

O valor médio das internações no SUS na RMR a preços corrigidos para 2016 pelo IGP-M é de R\$ 1.836,88 (DATASUS, 2012). Com o número de internações $(\Delta S)$ obtido pela fórmula de Lvovky estimaram-se os custos das internações hospitalares.

0 custo da poluição considera também os dias de trabalho perdidos por indisposições ou complicações que podem levar a internações por problemas cardiovasculares ou do aparelho respiratório.

A metodologia desenvolvida por Lvovsky (2000) permite estimar o total de dias perdidos em decorrência de uma elevada concentração de $\mathrm{MP}_{10}$. Aplica-se a mesma fórmula para calcular o $\Delta \mathrm{S}$ e o parâmetro b passa a ser 0,0575 . 0 custo estimado por dia de trabalho perdido foi calculado com base no rendimento médio mensal da RMR de R\$1.647,80, calculado pelo IBGE (2016). Dividindo esse valor por 22 dias de trabalho, obtêm-se um rendimento médio diário de $\mathrm{R} \$ 74,90$. Os valores das perdas por faltas ao trabalho e por internações hospitalares podem ser conferidos na Tabela 3.

Tabela 3: Custos decorrentes da poluição com internações hospitalares e faltas ao trabalho

\begin{tabular}{|c|c|c|c|c|c|c|c|}
\hline \multirow[b]{2}{*}{ Modo } & \multicolumn{3}{|c|}{ Internações hospitalares } & \multicolumn{3}{|c|}{ Faltas ao trabalho } & \multirow[b]{2}{*}{$\begin{array}{l}\text { Total de Perdas } \\
\text { com Poluição (R\$) }\end{array}$} \\
\hline & $\begin{array}{l}N^{\circ} . \text { de } \\
\text { Intern. } \\
(\Delta S) \\
\end{array}$ & $\begin{array}{c}\text { Valor } \\
\text { Médio } \\
(R S)\end{array}$ & $\begin{array}{l}\text { Valor Total } \\
\text { Internações } \\
(\mathrm{R} \$)\end{array}$ & $\begin{array}{l}N^{\circ} \text {. Dias de } \\
\text { Trabalho }(\Delta S)\end{array}$ & $\begin{array}{c}\text { Valor } \\
\text { Médio (R\$) }\end{array}$ & $\begin{array}{l}\text { Valor Total de } \\
\text { Faltas (R\$) }\end{array}$ & \\
\hline Automóvel & 2,40 & $1.836,88$ & $4.408,51$ & $11.478,73$ & 74,90 & $859.756,88$ & $864.165,39$ \\
\hline Ônibus & 19,40 & $1.836,88$ & $35.635,47$ & $92.955,24$ & 74,90 & $6.962 .347,48$ & $6.997 .982,95$ \\
\hline Motocicleta & 3,10 & $1.836,88$ & $5.694,33$ & $14.854,83$ & 74,90 & $1.112 .626,77$ & $1.118 .321,10$ \\
\hline
\end{tabular}

A seguir, calculou-se o custo por quilômetro por modo da amostra (Tabela 4).

Tabela 4: Custo médio de poluição na RMR por quilômetro

\begin{tabular}{cccccccc}
\hline Modo & Frota $^{1}$ & $\begin{array}{c}\text { Total de Perdas } \\
\text { com Poluição (R\$) }\end{array}$ & $\begin{array}{c}\text { Custo Anual por } \\
\text { Veículo (R\$) }\end{array}$ & $\begin{array}{c}\text { Número de } \\
\text { Pessoas por } \\
\text { Veículo }\end{array}$ & $\begin{array}{c}\text { Custo por } \\
\text { Pessoa (R\$) }\end{array}$ & $\begin{array}{c}\text { Distância Média } \\
\text { Anual Pesquisada } \\
\text { (Km) }\end{array}$ & $\begin{array}{c}\text { Custo } \\
\text { Médio por } \\
\text { Km (R\$) }\end{array}$ \\
\hline Automóvel & 718.560 & $864.165,39$ & 1,2 & 1,2 & 1 & $6.050,88$ & 0,0002 \\
Ônibus & 10.941 & $6.997 .982,95$ & 639,6 & 60 & 10,7 & $7.455,36$ & 0,0014 \\
Moto & 299.832 & $1.118 .321,10$ & 3,7 & 1,2 & 3,1 & $5.697,12$ & 0,0005 \\
\hline
\end{tabular}

Fonte: ${ }^{1}$ DENATRAN (2016) e ${ }^{2}$ Meira et al. (2014).

\subsubsection{Custos com acidentes}

Orsati et al. (2004) estimam que 37\% das internações por fratura são de acidentados no trânsito. Peden et al. (2004), em relatório para a Organização Mundial de Saúde (OMS), estimam que os acidentes de trânsito implicam um custo anual de $1 \%$ a $2 \%$ do PIB para os países menos desenvolvidos. No Brasil em 2014, o número de mortos em acidentes de trânsito foi 43.075, o número de feridos 600.000 (DATASUS, 2014) e o custo dos acidentes estimado pelo IPEA/ANTP (2003) em valores corrigidos para 2014, foi R\$ $277.397,76$ para acidentes com vítimas fatais e $\mathrm{R} \$ 33.523,20$ para acidentes com feridos. 0 total corresponde a um valor de R $\$ 32$ bilhões, ou aproximadamente 0,60\% do PIB brasileiro (ADVFN, 2016), desconsiderando acidentes sem vítimas.

De acordo com a última pesquisa do gênero realizada no Brasil, o custo médio dos acidentes com vítimas fatais a preços corrigidos para 2016 pelo IGP-M é de $\mathrm{R} \$ 322.185,94$, com vítimas feridas de $\mathrm{R} \$$ 38.935,80 e sem vítimas de $\mathrm{R} \$ 7.274,26$ (IPEA/ANTP, 2003).

Assim, o custo por modo de transporte foi considerado como sendo o custo de cada tipo de acidente multiplicado pela quantidade de acidentes ocorrida entre o quilômetro 60 e o quilômetro 80 da rodovia 
BR-101-PE (Tabela 5). Salienta-se que a rodovia BR-101-PE é a principal via arterial que atende à UFPE e essa quilometragem corresponde aos $10 \mathrm{~km}$ antes e após a UFPE. A rodovia se constitui, portando, na via de acesso de quase todos que acessam a universidade, excetuando-se apenas os que habitam nos seus arredores. Enfatiza-se que esse trecho da rodovia não tem características de tráfego rural e sim de tráfego urbano.

Tabela 5: Custo total de acidentes na BR-101-PE próximo à UFPE

\begin{tabular}{ccccc}
\hline Tipo & $\begin{array}{c}\text { Custo Médio por } \\
\text { Acidente }(\mathrm{R} \$)\end{array}$ & $\begin{array}{c}\text { No. de Acidentes: } \\
\text { Automóvel }\end{array}$ & $\begin{array}{c}\text { No. de Acidentes: } \\
\text { Ônibus }\end{array}$ & $\begin{array}{c}\text { №. de Acidentes: } \\
\text { Motocicleta }\end{array}$ \\
\hline Com vítimas fatais & $322.185,94$ & 4 & 0 & 6 \\
Com vítimas feridas & $38.935,80$ & 99 & 11 & 129 \\
Sem vítimas & $7.274,26$ & 628 & 44 & 13 \\
\hline Total por modo & & $\mathrm{R} \$ 9.711 .623,24$ & $\mathrm{R} \$ 748.361,24$ & $\mathrm{R} \$ 7.050 .399,22$ \\
\hline
\end{tabular}

Fontes: DNIT (2015) e IPEA (2003).

0 custo/km foi calculado com base na frota proporcional de veículos da RMR (DENATRAN, 2016) multiplicada pela quantidade de veículos que diariamente transitam na BR-101-PE nas imediações da UFPE (DNIT, 2010). Esse número foi ainda multiplicado por 22 dias úteis e 12 meses. Isso forneceu o número de veículos anuais na BR-101-PE próximo à UFPE. Dividindo o custo total, obtido na Tabela 5, por esse valor tem-se o custo por veículo. Dividindo pela distância média anual pesquisada tem-se o custo/km (Tabela 6).

Tabela 6: Custo de acidentes por quilômetro

\begin{tabular}{|c|c|c|c|c|c|c|c|c|}
\hline Modo & $\begin{array}{c}\mathrm{N}^{\circ} \text { de Veículos } \\
\text { na BR-101-PE } \\
\text { próximo à } \\
\text { UFPE/dia }{ }^{1}\end{array}$ & $\begin{array}{c}\mathrm{N}^{\circ} \text { de Veículos } \\
\text { na BR-101-PE } \\
\text { próximo à } \\
\text { UFPE/ano }\end{array}$ & $\begin{array}{l}\text { Custo Total } \\
\text { Anual com } \\
\text { Acidentes } \\
\text { (R\$) }\end{array}$ & $\begin{array}{l}\text { Custo } \\
\text { por } \\
\text { Veículo } \\
\text { (R\$) } \\
\end{array}$ & $\begin{array}{l}\text { Número de } \\
\text { Pessoas } \\
\text { por Veí- } \\
\text { culo² }^{2} \\
\end{array}$ & $\begin{array}{c}\text { Custo por } \\
\text { Pessoa } \\
\text { (R\$) }\end{array}$ & $\begin{array}{l}\text { Distância } \\
\text { Média Anual } \\
\text { Pesquisada } \\
(\mathrm{Km}) \\
\end{array}$ & $\begin{array}{l}\text { Custo } \\
\text { Médio } \\
\text { por Km } \\
(\mathrm{R} \$) \\
\end{array}$ \\
\hline Automóveis & 62.723 & 16.558 .872 & $9.711 .623,20$ & 0,59 & 1,20 & 0,49 & $6.050,88$ & 0,00008 \\
\hline Ônibus & 1.451 & 383.064 & $748.361,20$ & 1,95 & 60,00 & 0,03 & $7.455,36$ & 0,000004 \\
\hline Motocicleta & 25.826 & 6.818 .064 & $7.050 .399,20$ & 1,03 & 1,20 & 0,86 & $5.697,12$ & 0,0002 \\
\hline
\end{tabular}

Fontes: 'DENATRAN (2016) e DNIT (2010) e 2 Meira et al. (2014).

\subsubsection{Custos com congestionamentos}

Outra externalidade que precisa ser considerada é o custo gerado devido aos congestionamentos. No cálculo desses custos, duas situações foram consideradas: custo de oportunidade do tempo perdido pelas pessoas retidas no trânsito e gastos monetários causados pelo aumento no consumo de combustíveis.

Para calcular os custos de oportunidade primeiro calculou-se a renda mensal média de cada modo para a amostra. Os valores foram $\mathrm{R} \$ 2.980,72$ para os pedestres, $\mathrm{R} \$ 4.553,58$ para o automóvel, $\mathrm{R} \$$ $2.465,05$ para a bicicleta, $\mathrm{R} \$ 3.115,39$ para a motocicleta, $\mathrm{R} \$ 4.464,67$ para o usuário de táxi e $\mathrm{R} \$$ 2.913,06 para o usuário do transporte público. Em seguida mediu-se a variação entre o tempo real gasto pelos respondentes dos questionários e o tempo que poderia ser gasto caso a velocidade esperada fosse alcançada. Adotaram-se as velocidades médias sem congestionamentos de $50 \mathrm{~km} / \mathrm{h}$ para automóveis e de $30 \mathrm{~km} / \mathrm{h}$ para ônibus, conforme considerações feitas por Cintra (2014). A velocidade da bicicleta foi a mesma adotada por Kifer (2002). A diferença entre o tempo que poderia ser gasto e os tempos de deslocamento reais representa o tempo perdido nos congestionamentos. 0 custo de oportunidade é medido pelo valor da hora de trabalho multiplicado pelo tempo perdido dividido pela distância total (Equação 3).

$$
C_{o p}=\frac{P_{h r} \times \Delta T}{D}
$$


Onde:

$C_{o p}$ : custo de oportunidade.

$P_{h r}$ : preço da hora de trabalho.

$\Delta T$ : variação entre o tempo esperado e o tempo real.

$D$ : distância real percorrida.

Os valores obtidos estão na Tabela 7:

Tabela 7: Custo médio de congestionamento por quilômetro, por pessoa e por modo

\begin{tabular}{cccccccc}
\hline Modo & $\begin{array}{c}\text { Distância Média } \\
\text { Diária Pesquisada } \\
(\mathbf{K m})\end{array}$ & $\begin{array}{c}\text { Tempo Médio de } \\
\text { Deslocamento } \mathbf{D i}- \\
\text { ário (horas) }\end{array}$ & $\begin{array}{c}\text { Velocidade } \\
\text { Média } \\
(\mathrm{Km} / \mathrm{h})\end{array}$ & $\begin{array}{c}\text { Velocidade } \\
\text { Esperada } \\
(\mathbf{K m} / \mathbf{h})^{\mathbf{1}}\end{array}$ & $\begin{array}{c}\text { Tempo Diário Perdido } \\
\text { no Congestionamento } \\
\text { (horas) }\end{array}$ & $\begin{array}{c}\text { Hora de } \\
\text { Trabalho } \\
\text { (R\$) }\end{array}$ & $\begin{array}{c}\text { Custo } \\
\text { por Km } \\
\text { (R\$) }\end{array}$ \\
\hline Automóvel & 22,92 & 1,74 & 13,17 & 50,00 & 1,28 & 20,70 & 0,963 \\
Transp. Púb. & 28,24 & 2,63 & 10,74 & 30,00 & 1,69 & 13,24 & 0,013 \\
Motocicleta & 21,58 & 1,21 & 17,83 & 50,00 & 0,78 & 14,16 & 0,427 \\
Bicicleta & 6,96 & 0,75 & 9,28 & 15,00 & 0,29 & 11,20 & 0,460 \\
\hline
\end{tabular}

Fontes: Meira et al. (2014) e ${ }^{1}$ Cintra (2014).

Para estimar o custo adicional de combustível causado pelos congestionamentos foi retirada da amostra a distância média diária percorrida por cada modo. Na época da pesquisa, o preço da gasolina oscilava em torno de $\mathrm{R} \$ 3,00$ e o do diesel em torno de $\mathrm{R} \$ 2,60$ (ANP, 2015).

0 consumo de combustível foi estimado de acordo com a metodologia proposta pelo IPEA/ANTP (1998), que utiliza as seguintes funções:

Função de consumo de combustíveis pelos carros:

$$
C=0,09543+\frac{1,26643}{V}-0,00029 V
$$

Onde:

$C=$ Consumo $(\mathrm{l} / \mathrm{km})$.

$V=$ Velocidade $(\mathrm{km} / \mathrm{h})$.

Função de consumo de diesel pelos ônibus:

$$
C=0,44428+0,00008 V^{2}-0,00708 V+\frac{1,37911}{V}+0,00107 \mathrm{carr}
$$

Onde:

$C=$ Consumo $(\mathrm{l} / \mathrm{km})$.

$V=$ Velocidade $(\mathrm{km} / \mathrm{h})$.

Carr $=$ carregamento $($ sentado + em pé) .

Inserindo nessas funções os dados de Meira et al. (2014) e o preço da gasolina em 2014, foi estimado (Tabela 8) o custo por quilômetro para os modos automóvel, motocicleta e transporte público (ônibus). Para a motocicleta foi feita uma relação entre o consumo do automóvel tido como padrão na pesquisa, o GM Onix, de 7,6 km/l na cidade (Quatro Rotas, 2012) e a motocicleta-padrão, Honda CG 150, cujo consume é estimado em 46/km/l (Miotto, 2013). Considerou-se a ocupação (carregamento) do automóvel e da moto 1,2 passageiros e do ônibus em 60 pessoas. 0 custo médio por quilômetro é calculado multiplicando a variação de consumo pelo preço do litro de combustível, dividido pelo número de pessoas por veículo. 
Tabela 8: Custo médio de combustíveis por quilômetro, por pessoa e por modo

\begin{tabular}{|c|c|c|c|c|c|c|c|}
\hline Modo & $\begin{array}{l}\text { Velocidade } \\
\text { Média } \\
\text { (Km/h) }\end{array}$ & $\begin{array}{l}\text { Velocidade } \\
\text { Esperada } \\
(\mathrm{Km} / \mathrm{h})^{1}\end{array}$ & $\begin{array}{l}\text { Consumo } \\
\text { Real }(1 / \mathbf{k m})\end{array}$ & $\begin{array}{c}\text { Consumo sem } \\
\text { Congestionamento } \\
(\mathrm{l} / \mathrm{km})\end{array}$ & $\begin{array}{c}\text { Variação } \\
\text { Consumo } \\
(\mathrm{l} / \mathrm{km})\end{array}$ & $\begin{array}{l}\text { Número de } \\
\text { Pessoas por } \\
\text { Veículo }^{2}\end{array}$ & Custo por Km (R\$) \\
\hline Automóvel & 13,17 & 50,00 & 0,188 & 0,106 & 0,082 & 1,20 & 0,205 \\
\hline Ônibus & 10,74 & 30,00 & 0,570 & 0,414 & 0,156 & 60,00 & 0,007 \\
\hline Motocicleta & 17,83 & 50,00 & 0,031 & 0,018 & 0,013 & 1,20 & 0,033 \\
\hline
\end{tabular}

Fontes: Meira et al. (2014), TVJORNAL (2014) e ${ }^{1}$ Cintra (2014).

\subsubsection{Velocidade efetiva social (poluição, acidentes e congestionamentos)}

Somando-se os custos sociais resumidos nas tabelas 4, 6, 7 e 8 obtêm-se os seguintes custos sociais por modo de transporte: automóvel - $\mathrm{R} \$ 1,17 / \mathrm{km}$; ônibus - $\mathrm{R} \$ 0,02 / \mathrm{km}$; motocicleta - $\mathrm{R} \$ 0,47 / \mathrm{km}$; bicicleta - $\mathrm{R} \$ 0,46 / \mathrm{km}$; a pé - $\mathrm{R} \$ 0,00 / \mathrm{km}$; e táxi - $\mathrm{R} \$ 1,17 / \mathrm{km}$.

Multiplicando esses valores pelas duas viagens que se assumiu serem realizadas por usuário por dia, pela distância percorrida, por 22 dias úteis e por 12 meses por ano, obtêm-se os custos variáveis sociais totais. Neste caso, o custo para ônibus e táxis varia por quilômetro como os outros, pois não se considera a tarifa e sim a quantidade de acidentes, poluição e congestionamento causada. 0 custo total é composto pelo custo fixo anual somado ao custo variável e ao custo variável social por quilômetro multiplicado pela quantidade de quilômetros percorrida por ano. No caso estudado, o custo por quilômetro ficaria assim: automóveis $(\mathrm{R} \$ 2,65+\mathrm{R} \$ 1,17=\mathrm{R} \$ 3,82 / \mathrm{km})$; transporte público $(\mathrm{R} \$ 0,20+\mathrm{R} \$ 0,02=\mathrm{R} \$$ $0,22 / \mathrm{km}) ;$ motocicleta $(\mathrm{R} \$ 0,56+\mathrm{R} \$ 0,47=\mathrm{R} \$ 1,03 / \mathrm{km}) ;$ bicicleta $(\mathrm{R} \$ 0,08+\mathrm{R} \$ 0,46=\mathrm{R} \$ 0,54 / \mathrm{km}) ; \mathrm{a}$ pé $(\mathrm{R} \$ 0,00+\mathrm{R} \$ 0,00=\mathrm{R} \$ 0,00 / \mathrm{km})$; e táxi $(\mathrm{R} \$ 2,96+\mathrm{R} \$ 1,17=\mathrm{R} \$ 4,13 / \mathrm{km})$. Assim, usando a mesma metodologia empregada na velocidade efetiva, calculou-se a velocidade efetiva social. Os resultados podem ser observados na Tabela 9.

Tabela 9: Cálculo da velocidade efetiva social (universo da amostra)

\begin{tabular}{cccccc}
\hline Modo & $\begin{array}{c}\text { Distância Média } \\
\text { Diária Pesquisada } \\
(\text { Km) }\end{array}$ & $\begin{array}{c}\text { Tempo de Trabalho } \\
\text { (horas) }\end{array}$ & $\begin{array}{c}\text { Tempo Médio de } \\
\text { Deslocamento Diário } \\
\text { (horas) }\end{array}$ & $\begin{array}{c}\text { Velocidade } \\
\text { Efetiva Social } \\
\text { (km/h) }\end{array}$ & Ranking \\
\hline Automóvel & 22,92 & 4,36 & 1,74 & 3,76 & 50 \\
Transporte Público & 28,24 & 0,31 & 2,63 & 9,61 & 10 \\
Motocicleta & 21,58 & 1,11 & 1,21 & 9,30 & 20 \\
Bicicleta & 6,96 & 0,21 & 0,75 & 7,25 & 40 \\
A pé & 5,68 & 0,00 & 0,68 & 8,35 & 30 \\
Táxi & 14,66 & 3,01 & 1,44 & 3,29 & 60 \\
\hline
\end{tabular}

\section{ANÁLISE DOS RESULTADOS}

Ao analisar os custos sociais (custos das externalidades) por quilômetro estimados dos diversos modos de transportes utilizados para acesso à UFPE, observa-se que apesar de significativos, apresentam menores proporções em relação aos custos totais, do que os relatados por Ker e James (2000) e Litman (2006). Os custos sociais da amostra pesquisada representam $45 \%$ dos custos privados, ou $31 \%$ dos custos totais, enquanto Ker e James (ibid) estimam custos aproximadamente equivalentes ou 50\% superiores aos custos privados, como relata Litman (ibid).

Ainda analisando os resultados do transporte individual por automóvel ou táxi, observa-se que estes impõem um custo de externalidades negativas aos demais usuários e à população em geral de $\mathrm{R} \$$ 1,17/km percorrido. Considerando-se a extensão média diária percorrida da amostra de 22,92 km com uma ocupação de 1,2 pessoas por veículo, chega-se a uma estimativa do custo de externalidade diário devido à sociedade por veículo de aproximadamente $\mathrm{R} \$ 22,00$.

Por outro lado, o transporte público, em face da sua produtividade, com um custo de externalidade 
de $\mathrm{R} \$ 0,02$ por passageiro-quilômetro apresenta impacto externo quase sessenta vezes menor do que o transporte por automóvel. Os custos sociais das bicicletas ( $\mathrm{R} \$ 0,46 / \mathrm{km})$, que se esperavam mais baixos, decorrem das baixas velocidades atingidas em tráfego não segregado, que acarretam aumentos nos tempos de viagem.

Com relação às estimativas das velocidades efetivas, destaca-se também o transporte público como o de maior valor $(9,65 \mathrm{~km} / \mathrm{h})$, seguido das motocicletas $(9,30 \mathrm{~km} / \mathrm{h})$, pelo baixo custo de aquisição e manutenção e por viagens a pé $(8,35 \mathrm{~km} / \mathrm{h})$, pelas pequenas distâncias percorridas. As viagens por automóveis $(3,76 \mathrm{~km} / \mathrm{h})$ e táxis $(3,29 \mathrm{~km} / \mathrm{h})$ apresentam-se como de mais baixo valor social, situação que já se configurava quando a análise foi feita apenas considerando os custos privados (velocidade efetiva).

\section{CONCLUSÕES}

Com a demonstração prática do conceito de velocidade efetiva social, a partir da percepção de que o excesso de utilização do transporte individual sobre bens escassos, como as vias públicas, causa falhas de mercado representadas por congestionamentos, acidentes, poluição e perdas de horas produtivas, atinge-se o objetivo proposto desta pesquisa. Esses problemas constatados podem ser eficientemente atenuados por uma política de cobrança aos causadores dos custos não contabilizados a terceiros, dos quais os mais significativos, conforme os resultados obtidos, são custos decorrentes do tempo perdido em congestionamentos. A incorporação desses custos aumentaria o custo generalizado de transporte aos modos individuais, apontando para a redução de sua utilização com transferência de muitos usuários a alternativas mais viáveis econômica e socialmente, podendo ser o transporte público, a bicicleta ou as caminhadas. Reconhece-se, no entanto, a provável resistência a mudanças de hábitos de atores diversos impostos por políticas públicas, conforme já relatado por Takahashi (2004), que leva à necessidade de soluções de compromisso, nas quais as partes cedem pela percepção de que socialmente não é possível atender a todas as conveniências individuais.

Este artigo, ao contabilizar esses custos e apontar as perdas da efetividade social das velocidades, extrapola a visão individualizada de custos de transportes e expande para a percepção dos custos não remunerados impostos a terceiros, trazendo um forte argumento para politicamente justificar a implantação de instrumentos legais disponíveis de redução dessa iniquidade. Pode-se, então, reforçar as justificativas para utilização por parte dos gestores municipais dos instrumentos apontados no Artigo 5 da Lei no. 12.587/2012, que trata da justa distribuição dos benefícios e ônus decorrentes do uso dos diferentes modos e serviços de transportes.

Com esse enfoque, os gestores públicos deveriam se preocupar em mostrar à sociedade os enormes custos sociais que $o$ atual modelo de mobilidade urbana brasileiro impõe às atuais e futuras gerações. 0 conceito de velocidade efetiva social parece ser uma boa alternativa para mudar tal realidade, pois apresenta argumentos econômicos em nível individual e coletivo que demonstram as perdas aparentemente ocultas decorrentes das escolhas modais. Como instrumento de políticas públicas, imagina-se que uma regulação restritiva ao transporte individual, apoiada pela conscientização através de campanhas publicitárias e outros instrumentos de mídia, tenha o poder de informar e promover mudança de hábitos nas pessoas com a utilização de modos mais sustentáveis de transporte. As mudanças para modos socialmente mais eficientes têm o poder de reduzir os custos individuais e coletivos com vítimas de acidentes de trânsito e de doenças decorrentes da poluição, além das perdas econômicas e de produtividade decorrentes dos efeitos dos congestionamentos.

No entanto, medidas de desestímulo econômico ao uso do transporte individual precisam ser reforçadas com ações de melhoria das condições das alternativas mais sustentáveis, através de mais eficiência no sistema de transporte público, melhorias das condições de mobilidade e acessibilidade nos passeios e na infraestrutura para o uso de bicicletas, para torná-los mais atrativos e seguros. Ainda com base nesse conceito no âmbito do Campus da UFPE, onde foi realizada a pesquisa, propõem-se uma série de medidas que visam modificar o perfil médio das escolhas modais. Tais medidas visam em princípio aumentar os custos de utilização do transporte individual por uma restritiva regulamentação dos esta- 
cionamentos nas vias de circulação e a institucionalização de um sistema de estacionamento rotativo pago nas áreas regulamentadas. Por outro lado, para estimular os modos mais sustentáveis propõe-se nas áreas internas e do entorno imediato: a implantação de um sistema adequado de ciclovias, ciclofaixas e bicicletários; melhorias nas condições de acessibilidade e de iluminação públicas nos passeios e trilhas de pedestres; e melhorias nas instalações de apoio e na oferta de linhas de transporte público.

Nesta pesquisa, entre 80 e $90 \%$ dos custos das externalidades provêm das perdas de horas produtivas. Entretanto, os valores desses custos são ainda inferiores aos relatados por Ker e James (2000) e Litman (2006), nos quais as externalidades excedem os custos diretos de transportes aos usuários. Pesquisas posteriores poderiam aprofundar os levantamentos de outros custos ambientais. Sugere-se a incorporação de outros agentes poluidores além das partículas finas $\left(\mathrm{MP}_{10}\right)$, como dióxido de carbono $\left(\mathrm{CO}_{2}\right)$ e metano $\left(\mathrm{CH}_{4}\right)$ - causadores do efeito estufa; e óxido de enxofre $\left(\mathrm{SO}_{\mathrm{x}}\right)$, monóxido de carbono (CO) e óxido de nitrogênio - que têm poder de causar doenças respiratórias, circulatórias, alérgicas e vários tipos de câncer. Certamente essas novas análises aumentarão o impacto dos custos ambientais na elevação da velocidade efetiva social dos transportes motorizados, demonstrando ainda mais a necessidade de mudança de paradigmas.

Como propostas para futuras pesquisas, sugere-se a replicação desta pesquisa em outras IES e em outras regiões metropolitanas brasileiras, considerando ainda separadamente as faixas de renda e os meios de transporte.

\section{REFERÊNCIAS}

ADVFN (2016). PIB - produto interno bruto. Disponível em: <http://br.advfn.com/indicadores/pib>. Acesso em: jan. 2016.

ANP (2015). Preços do petróleo, gás natural e combustíveis nos mercados nacional e internacional. Boletim Anual de Preços2015.

Ávila, L. (2016). Planilha para calcular custos de ter um carro. clube dos poupadores. Disponível em <www.clubedospoupadores.com/ferramentas/planilha-calcula-custos-de-um-carro-para-excel.html>. Acesso em: jan. 2016.

Brasil (2004). Política nacional de desenvolvimento urbano. Brasília, DF: Ministério das Cidades, Disponível em: <www.unc.br/mestrado/mestrado_materiais/1PoliticaNacionalDesenvolvimentoUrbano.pdf>. Acessado em agosto de 2015.

Brasil (2007). Metodologia integrada de suporte ao planejamento, acompanhamento e avaliação dos programas nacionais de transporte. Brasília - DF: Ministérios dos Transportes. Disponível em: <www.researchgate.net/publication/282668271_Metodologia_Integrada_de_Suporte_ao_Planejamento_Acompanhamento_e_Avaliacao_dos_Programas_Nacionais_de_Transporte_-_Relatorio_Sintese>. Acesso em: nov. 2016.

Brasil (2012). Lei n. 12.587/2012 de 3 de janeiro de 2012, institui as diretrizes da Politica Nacional de Mobilidade Urbana. Diário Oficial da União - Seção 1 - 4 jan. 2012, Página 1

Castro, C.U. (2007). Transporte público urbano: a tarifa única no município de Florianópolis. Monografia, 57p. Universidade Federal de Santa Catarina. Florianópolis - SC. Disponível em <https://repositorio.ufsc.br/bitstream/handle/123456789/122074/document-12.pdf?sequence=1\&isAllowed=y>. Acesso em: jun. 2015.

CETESB, (2015). Qualidade do ar no estado de São Paulo. Série Relatórios 134p, São Paulo.

Cintra, M. (2014). Os custos com congestionamentos na Cidade de São Paulo. São Paulo, Working Paper , n. 356.

DATASUS (2012). E.11 Valor médio pago por internação hospitalar no SUS (AIH), ano 2012, região metropolitana do Recife, hospitalização normal. Disponível em: < http://tabnet.datasus.gov.br/cgi/tabcgi.exe?idb2012/e11.def >. Acesso em: jun. 2016

DATASUS (2014). Acidentes, estatísticas nacionais. Disponível em: <http://www.vias-seguras.com/layout/set/print/os_acidentes/estatisticas/estatisticas_nacionais>. Acesso em: mar. 2016.

DENATRAN (2016). Frota veicular brasileira. Brasília - DF : Denatran. Disponível em: <www.denatran.gov.br/frota.htm> Acesso em: abr. 2016.

DNIT (2010). Contorno de Recife recebe obras de restauração. Disponível em: <www.dnit.gov.br/noticias/dnit-restaura-segmento-urbano-da-br-101-em-pernambuco>. Acesso em: abr. 2016.

DNIT (2015). Estatística de acidentes. Disponível em: < http://www.dnit.gov.br/rodovias/operacoes-rodoviarias/estatisticasde-acidentes>. Acesso em: fev. 2016.

Euroforum (2007). Draft paper: state of the art of research and development in the field of urban mobility. European Research Forum for Urban Mobility. Disponível em: <www.emta.com/IMG/pdf/SoA_FinalDraft_160207_FINAL.pdf>. Acesso em: jan. 2016.

GM (2016). Chevrolet onix: monte o seu. general motors do Brasil. Disponível em <www.chevrolet.com.br/carros/onix/monte-o-seu.html?x-state=SP\&x-regionid=1>. Acesso em: jan. 2016. 
Graham-Rowe, E.; B. Gardner; C. Abraham; S. Skippon; H. Dittmar; R. Hutchins e J. Stannard (2012). Mainstream consumers driving plug-in battery-electric and plug-in hybrid electric cars: a qualitative analysis of responses and evaluations. Transportation Research Part A: Policy and Practice, v. 46, n. 1, p. 140-153. DOI: 10.1016/j.tra.2011.09.008

Hao, H; H. Wang; e M. Ouyang (2011). Comparison of policies on vehicle ownership and use between Beijing and Shanghai and their impacts on fuel consumption by passenger vehicles. Energy Policy, v. 39, n. 2, p. 1016-1021. DOI: 10.1016/j.enpol.2010.11.039

Halek, F., Kavousi, A., \& Hassani, F. (2009). Evaluation of indoor-outdoor particle size distribution in Tehran's elementary schools. World Acad of Sci Eng and Tech, n. 57, p. 463-466. Disponível em: <scholar.waset.org/1999.2/8988>. Acesso em: jan. 2016.

IBGE (2015). Cidades. Disponível em: <http://cidades.ibge.gov.br/>. Acesso em: mar. 2016.

IBGE (2016). Pesquisa mensal de emprego - PME: região metropolitana do Recife. Disponível em: <http://www.ibge.gov.br/home/estatistica/indicadores/trabalhoerendimento/pme_nova/pme_201602pe_02.shtm>. Acesso em: mar. 2016.

Illich, I. (1974). Energy and equity. London: Calder \& Boyars.

IPEA/ANTP (1998). Redução das deseconomias urbanas com a melhoria nos transportes públicos. Brasília: IPEA.

IPEA/ANTP (2003). Impactos sociais e econômicos dos acidentes de trânsito nas aglomerações urbanas brasileiras: relatório executivo/IPEA, ANTP. - Brasília: IPEA: ANTP, 2003.

IPEA (2012). A nova lei de diretrizes da política nacional de mobilidade urbana. Handout no. 128. Disponível em <www.ipea.gov.br/portal/images/stories/PDFs/comunicado/120106_comunicadoipea128.pdf>. Acesso em: mar. 2012

Ker, I.; e James, B. (2000). The benefits of driving less evaluation of the travelsmart pilot project in south perth. Report 396. Perth, Western Australia: Transport WA.

Kifer, K. (2002). Auto costs versus bike costs, ken kifer's bike pages. Disponível em: <www.kenkifer.com/bikepages/advocacy/autocost.htm>. Acesso em: 03 jan. 2015.

Knight, V.M., \& Young, C.E.F. (2006). Custo da poluição gerada pelos ônibus urbanos na RMSP. Rio de Janeiro: ANPEC.

Leite, M.S.; e E.A. Ferreira (2014). Estudo da velocidade efetiva para diferentes níveis de renda e modos de transporte. CONGRESSO DA ASSOCIAÇÃO NACIONAL DE PESQUISA E ENSINO EM TRANSPORTES, 28., 2014. Anais... Curitiba: ANPET.

Lima, J.H.; L.H. Meira; M.O. Andrade; e M.L.A. Maia (2015). Tornando a escolha do modo economicamente racional: um estudo para o maior polo gerador de viagens da Região Metropolitana do Recife. CONGRESSO DA ASSOCIAÇÃO NACIONAL DE PESQUISA E ENSINO EM TRANSPORTES, 29., 2015. Anais... Ouro Preto: ANPET.

Lima Neto, V.C.; Carvalho, C.H.R.; e Balbim, R.N. (2014). Mobilidade urbana: o Brasil em transformação: o papel do IPEA na construção do pacto da mobilidade: Brasil em desenvolvimento 2014: Estado, planejamento e políticas públicas. Brasília: IPEA.

Litman, T. (2006). Transportation cost and benefit analysis: techniques, estimates and implications. Victoria, British Columbia.: Victoria Transportation Policy Institute. Disponível em <www.vtpi.org/tca>. Acesso em: mar. 2016.

Lvovsky, K. et. al. (2000). Environmental costs of fossil fuels: a rapid access method with application to six cities. Paper $n^{\circ} 78$ da Pollution Management Series. Banco Mundial. Disponível em http://www-wds.worldbank.org/external/default/WDSContentServer/WDSP/IB/2002/09/07/000094946_02081904011759/Rendered/PDF/multi0page.pdf. Acesso em: 07 mar. 2016.

Marín, L.; e M.S. Queiroz (2000). A atualidade dos acidentes de trânsito na era da velocidade: uma visão geral. Caderno de Saúde Pública, Rio de Janeiro, v. 16, n. 1. DOI: 10.1590/S0102-311X2000000100002.

Marques da Costa, N. M. S. (2007). Mobilidade e transporte em áreas urbanas: o caso da área metropolitana de Lisboa. Tese (Doutorado) - Universidade de Lisboa. Lisboa.

Meira, L.H.; M.L.A. Maia; M.O. Andrade; e A. Brasileiro (2014). A influência da qualidade do transporte público na rotina acadêmica: o caso da Universidade Federal de Pernambuco. CONGRESSO DA ASSOCIAÇÃO NACIONAL DE PESQUISA E ENSINO EM TRANSPORTES, 28., 2014. Anais.... Curitiba - PR: ANPET.

Merlin, P. (1985). La Planification des transports urbains. Paris, Masson. Espace géographique, v. 14, n. 1, p. 76-77.

Miotto, R. (2013). Primeiras impressões: Honda CG 150 Fan e Titan. Reportagem do G1 de 31 de julho de 2013. Disponível em: <http://g1.globo.com/carros/motos/noticia/2013/07/primeiras-impressoes-honda-cg-150-fan-e-titan.html>. Acesso em: abr. 2016.

Morawska, L., He, C., Hitchins, J., Gilbert, D., \& Parappukkaran, S. (2001). The relationship between indoor and outdoor airborne particles in the residential environment. Atmospheric Environment, v. 35, n. 20. DOI: 10.1016/S13522310(01)00097-8.

Orsati, F.T., Machado, F.S., Kitayama, M.M.G., \& Bruscato, W.L. (2004). Estudo da população fraturada, devido a acidentes de trânsito, internada na Santa Casa de São Paulo. Psicologia Hospitalar, v. 2, n. 2.

Ostro, B., \& Chestnut, L. (1998). Assessing the health benefits of reducing particulate matter air pollution in the United States. Environmental Research, v. 76, n. 2, p. 94-106. DOI: 10.1006/enrs.1997.3799

Peden, M., Scurfield, R., Sleet, D., Mohan, D., Hyder, A.A., Jarawan, E., \& Mathers, C. (2004). World report on road traffic injury prevention. Geneva: World Health Organization; 2004.

Petruccelli, U. (2015). Assessment of external costs for transport project evaluation: Guidelines in some European countries. Environmental Impact Assessment Review, v. 54, p. 61-71. DOI: 10.1016/j.eiar.2015.05.004

Quatro Rodas (2012). Teste de pista: Chevrolet Onix. Disponível em <http://quatrorodas.abril.com.br/materia/chevrolet-onix725300>. Acesso em: maio 2016. 
Ragazzo, C., Lima, J. (2013). Urban planning and traffic reduction: the Nossa Senhora da Paz subway station case in Ipanema. Brazilian Journal of Urban Management, v. 5, n. 2, p. 97-113. DOI: 10.7213/urbe.05.002.AC02

Roseiro, M.N.V. (2003). Poluentes atmosféricos: algumas consequências respiratórias na saúde humana. São Paulo: UNAERP.

Takahashi, R.H.C. (2004). A estrutura da decisão política na formulação de políticas públicas. Belo Horizonte - MG: Instituto de Estudos Avançados Transdisciplinares (IEAT).

Tranter, P.J. (2004). Effective speeds: car costs are slowing us down. Canberra : Department of the Environment and Heritage. Disponível em <www.greenhouse.gov.au/tdm/publications/pubs/effectivespeeds.pdf>. Acesso em: jan. 2016.

Tranter, P.J. (2010). Speed kills: the complex links between transport, lack of time and urban health. Journal of Urban Health: Bulletin of the New York Academy of Medicine, v. 87, n. 2. DOI:10.1007/s11524-009-9433-9.

Tranter, P.; e Ker, I. (2007). A wish called \$quander. In: EFFECTIVE SPEED AND EFFECTIVE WELLBEING IN AUSTRALIAN CITIES, 2007. Proceedings... National Conference (pp. 28-30).

VTPI (2013). Transport cost and benefit analysis II : travel time costs. Victoria, British Columbia : Victoria Transport Policy Institute, p.5.2 - 22. Disponível em: <www.vtpi.org/tca/tca0502.pdf>. Acesso em: dez. 2016. 